\title{
An Eclectic Phraseological Research on the Formation and Degrammaticalization of Phraseological Units
}

\author{
Ai Inoue ${ }^{1}$ \\ ${ }^{1}$ Department of Foreign Languages, National Defense Academy of Japan, Japan \\ Correspondence: Ai Inoue, Department of Foreign Languages, National Defense Academy of Japan, Japan. \\ E-mail: aiinoue@nda.ac.jp
}

Received: June 5, 2016 Accepted: June 27, 2016 Online Published: July 13, 2016

doi:10.5539/ijel.v6n4p1 URL: http://dx.doi.org/10.5539/ijel.v6n4p1

\begin{abstract}
This paper reveals new features of certain phraseological units (PUs) through bottom-up and top-down examination. Previous phraseological research has tended to focus on the PUs characteristically observed in a genre or context or how PUs semantically and syntactically behave to improve communicative competence. However, previous phraseological research has failed to give systematic explanations as to the formation of PUs and the process and conditions necessary for a word-combination to become a PU. By applying existing word-formation rules to various PUs, this study clarifies the formation and formation process for PUs and the four conditions required for a word combination to become a PU. It was found that although the word-formation rules are used, PUs generally arise in an unformed manner. Further, word-combinations are used as PUs only if they undergo a formation process and abide by the four conditions. PU features were found to be function words from a degrammaticalization standpoint. It has been widely accepted that degrammaticalization occurs in words. However, no research to date has dealt with the application of degrammaticalization to PUs. It was found that semantic degrammaticalization occurs in PUs arising from function words.
\end{abstract}

Keywords: phraseology, phraseological units, formations, function words, degrammaticalization

\section{Introduction}

This study (i) uses a bottom-up method to examine how phraseological units (PUs), which are frequently-used word-combinations of at least two words, are formed, what processes lie behind the formation of PUs, and what conditions are necessary to be used as PUs; and (ii) uses a top-down method to examine how PUs made up of function words cause degrammaticalization.

There were three main reasons for this study. First, a great deal of attention has been paid to grammaticalization; that is, when lexical items change into grammatical items. However, the opposite phenomenon, degrammaticalization, has not been actively studied, so the application of degrammaticalization is quite limited. Second, as degrammaticalization primarily deals with changes in words from grammatical to lexical items from a historical viewpoint, persuasive research regarding the degrammaticalization of PUs has not been conducted. Lastly, phraseology has revealed the outward features of each PU such as the meaning, tone, and syntactic function in a context; however, the internal features, or how PUs are formed, are unclear. Also, there has been little research into what happens after a word-combination becomes used as a PU. Therefore, only some distinctive parts of PUs have been given attention, but there is a lack of total accountability for PUs, as pointed out by Johansson (1985) and Leech (1992). Consequently, this study contributes to the systematization of phraseology and the advancement of degrammaticalization.

\section{Previous Research}

This section summarizes the phraseological research over the last decade, and then focuses on previous research on word-formation rules and degrammaticalization, which were the background source materials behind the PUs discussed later in this study.

\subsection{Phraseological Research}

The phraseological research can be divided into three phrases.

(1) a. the first phase (from 2003 to 2006): the focal point of the research was on explaining the polysemy and 
multifunctionality of existing PUs such as you know what, here we go/here we go again, and let's say.

b. the second phase (from 2006 to 2010): attention was paid to the differences and connections between existing similar PUs, for example, go and do/go to do/go do, and yet/but yet/yet, how come ...? ? why ...?

c. the third phrase (from 2006 to present): introduced newly-observed PUs until to, up until to, from $A$ until to $B$, it looks that-clause, though A but B, not A though A'but B, not only A though A'but B, in and of itself, in and of, be on against, be in and out, be in to, pirate version, should, oughts (auxiliary verbs become used as a noun), those that signifying people and to show their actual behavior.

The PUs in $(1 \mathrm{a}, \mathrm{b})$ have been in use for some time, but previous research has failed to present the real picture. Therefore, a re-examination of existing PUs was conducted. Research focused on (1c) has investigated the manner by which the newly-observed PUs developed from $(1 \mathrm{a}, \mathrm{b})$. Through all the phases, the stress pattern rules for the PUs (Note 1) are as shown in (2).

(2) a. it is impossible to predict the stress patterns of phrases simply by means of whether a word is a function word or a content word

b. stress is placed on the word that a speaker feels has the most important meaning

c. set phrases have stable stress patterns as words do

d. set phrases do not necessarily consist of one tone group with each word consisting of a set of phrases for each tone group (Inoue, 2009, p. 133)

As it now stands, the rules in (2) can be applied to any PUs.

The PUs in (1) can be classified into two types according to their components: (3a) when PUs develop from content words (Note 2) and function words (Note 3) and (3b) PUs consisting of only function words.

(3) a. you know what, here we go/here we go again, let's say, go and do/go to do/go do, and yet/but yet/yet, how come ...? / why ...?, it looks that-clause, pirate version, those that

b. until to, up until to, from A until to B, though A but B, not A though A' but B, not only A though A' but B, in and of itself, in and of, be on against, be in and out, be in to, should, oughts

It can be assumed from (3b) that newly-observed PUs are formed from existing words or function words. This is the same as a phenomenon called Kenning used in Old English. While it is easy to understand Kenning, no research explains why it is function words rather than content words that are put together in newly-observed PUs. Gray \& Biber (2015, p. 136) claimed that: "English is typologically unusual in that it has an incredibly rich inventory of function words...These lexical sequences (i.e., continuous or discontinuous lexical phrases) and frames consist mostly of different combinations of function words. However, it is not entirely clear whether these patterns should be taken to show a universal reliance on prefabricated phrases, or whether they reflect the typological characteristics of English grammar." This study answers the question as to why newly-observed PUs are comprised of function words.

\subsection{Word-Formation Rules}

Many studies have outlined word-formation rules (Allen, 1978; Bauer, 1983; Bybee, 1985; Ito \& Sugioka, 2002; Lieber, 1983; Pinker, 1994; Plag, 2003; Siegel, 1974; Nishikawa, 2013, Yamauchi \& Kitabayashi, 2014, etc.). (4) summarizes the shared common word-formation rules from previous research.
(4) a. compounding
b. derivation
c. borrowing
d. conversion
e. acronym
f. backformation (Note 4)
g. shortening
h. blending
i. lexicalization of phrases (Note 5)
j. metaanalysis
k. root creation 
As is shown in (4), it is natural to assume that new words are coined by putting existing words together or that existing words are processed and then used widely. As mentioned above, the technique, Kenning, is applied. Rules (4a, b, e, f) are highly productive. New words are generated based on the rules in (4), but this does not mean that such rules cover all instances as there is blocking which hampers the production of new words, as shown in (5).

(5) a. avoidance of phonological similarity, e.g., John *Dodged/*Forded/ Cheivedto New York. (The words, dodge and ford are already used, so phonologically it is difficult to tell them apart from *Dodged and *Forded.)

b. avoidance of morphological similarity, e.g., John decided to *United/ *United-Airlines to L.A. (The reason why the sentence is not acceptable is that *United is the same as the ending of the verb, unite.) John decided to American'd/ UA'd to L.A.

c. avoidance of semantic overlapping, e.g., *despise (n.) contempt (n.)

The PUs discussed in this study are different from those generated using the rules in (4) in that the PUs are formed from only free morphemes rather than bound morphemes.

\subsection{Degrammaticalization}

Degrammaticalization is when there is either a change from an affix to a clitic or a change from a function word to a content word. While it is known that degrammaticalization is the opposite to grammaticalization (when lexicon becomes grammar), as Norde $(2009$, p. 112) noted, "degrammaticalization is not the mirror image of grammaticalization in the sense that it cannot be the complete reverse of a grammaticalization chain, neither on the token nor on the type level."

Degrammaticalization refers to two cases: a theory concerning degrammaticalization and the degrammaticalization process. Regrammaticalization (Note 6), antigrammaticalization (Note 7), and lexicalization (Note 8) are used as the hyponyms of degrammaticalization. While research on grammaticalization has been actively conducted, little research has been done on degrammaticalization, so satisfactory explanations are lacking. This study explains degrammaticalizationwith reference to Norde $(2009,2010)$.

Lehmann (1982) first introduced the concept of degrammaticalization as shown in (6).

(6) Various authors (Givón, 1975, p. 96; Langacker, 1977, p. 103f.; Vincent, 1980, pp. 50-60) have claimed that grammaticalization is unidirectional; that is, an irreversible process $[\ldots]$ there is no degrammaticalization. (Lehmann, 1982, p. 16)

However, through the discussion and research from 1982 to the present, the study into degrammaticalization has moved from non-existence to a widely-acknowledged process.

Norde (2009) defined degrammaticalization as shown in (7) and demonstrated that the cline to degrammaticalization is in the opposite direction to grammaticalization (i.e., affix to the clitic or from a grammatical word to a content item), as discussed in Hopper and Traugott (2003, p. 7). Care must be taken in (8) that degrammaticalization does not always undergo all right-to-left movements on the cline. On the other hand, if the shift from the left to the right is not observed, grammaticalization cannot occur due to one of the features of degrammaticalization referred to as "discontinuity," which means that there is no domino effect, as is discussed later.

(7) Degrammaticalization is a composite change whereby a gram (Note 9) in a specific context gains in autonomy or substance on more than one linguistic level (semantics, morphology, syntax, or phonology) (Norde, 2009, p. 120)

(8) content item $>$ grammatical word $>$ clitic $>$ inflectional affix $(>\varphi)($ Norde, 2009, p. 8, 121)

(9) shows the three types of degrammaticalization.

(9) a. degrammation

b. deinflectionalization

c. debonding

Degrammation is "a composite change whereby a function word in a specific linguistic context is reanalyzed as a member of a major word class, acquiring the morphosyntactic properties which are typical of that word class, and gaining in semantic substance" (Norde, 2009, p. 135). Deinflectionalization in (9b) is "a composite change whereby an inflectional affix in a specific linguistic context gains a new function, while shifting to a less bound morpheme type" (Norde, 2009, p. 152). In (9c), debonding is "a composite change whereby a bound morpheme 
in a specific linguistic context becomes a free morpheme" (Norde, 2009, p. 187).

There are four basic characteristics for the degrammaticalization in (9): (i) counterdirectionality, (ii) novelty, (iii) infrequency, and (iv) discontinuity. Counterdirectionality shows a single shift from right to left, as in (8). Novelty means that the new word acquires a novel gram. Infrequency is the striking difference between grammaticalization and degrammaticalization. Degrammaticalization studies are far outnumbered by grammaticalization studies. Discontinuity shows that degrammaticalization includes at least one right-to-left movement on the cline of (8); of course there may be subsequent changes, but in general only a single shift is observed.

The three types in (9) can be classified into primary degrammaticalization, where a function word becomes a full lexical item, and secondary grammaticalization, where a bound morpheme becomes less grammatical. In (9a), degrammation is applicable to the former and deinflectionalization and debonding to the latter.

Norde (2009, p. 133) found that the three types shown in (9) can be observed on the levels shown in (10).

(10) a. Content level: shift from grammatical content to lexical content. Degrammaticalization at the content level is primary degrammaticalization and will be termed "degrammation".

b. Content-syntactic level: shift from "more grammatical" to "less grammatical", or movement out of a paradigm accompanied by a change in grammatical content. Degrammaticalization at the content-syntactic level is the first subtype of secondary degrammaticalization and will be termed "deinflectionalization".

c. Morphosyntactic level: shift from bound morpheme (affix, clitic) to free morpheme. This is the second subtype of secondary degrammaticalization and will be termed "debonding".

(11) shows the degrammaticalization parameters. These degrammaticalization parameters do not necessarily apply to all instances of degrammaticalization.

(11) a. integrity: A degrammaticalized item can be expected to gain semantic and phonological substance.

b. paradigmaticity: It signifies movement from a closed word class to an open word class in primary degrammaticalization, and it refers to discharge from an inflectional paradigm in secondary degrammaticalization.

c. paradigmatic variability: Degrammaticalization can also be expected to go hand in hand with increasing paradigmatic variability, or becoming optional in specific morphosyntactic contexts.

d. structural scope: Where scope has proved a problematic parameter in grammaticalization, it appears to be no less so in degrammaticalization. For the time being however, degrammaticalization will be expected to involve scope expansion.

e. bondedness: It is typically found in secondary degrammaticalization. In deinflectionalization, inflectional affixes may become either enclitic or derivational. In debonding, bound morphemes become free morphemes, accompanied by a change in meaning or function, or without such change.

f. syntagmatic variability: An increase in syntactic freedom. (Norde, 2009, p. 130f.)

Based on the characteristics of degrammaticalization as discussed in Norde (2009), the definition, process, types, and parameters for the degrammaticalization adopted in this study are as follows:

(12) a. definition: a composite change whereby a gram in a specific context gains in autonomy or substance on more than one linguistic level (semantics, morphology, syntax, or phonology)

b. process: inflectional affix ->clitic -> grammatical word -> content item

Please note that it is enough that a single shift from left to right occurs.

c. types: degrammaticalization

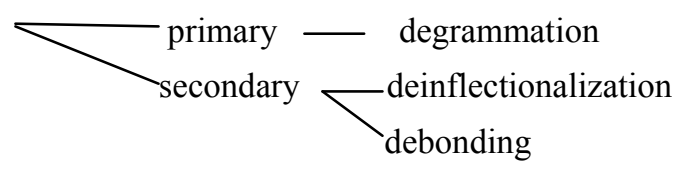

d. parameters: integrity, paradigmaticity, paradigmatic variability, structural scope, bondedness, and syntagmatic variability

\section{PUs-Formation, Processes, and Conditions}

Using word-formation rules, this section examines how PUs are formed, what processes a word combination has to undergo to become an established PU, and what conditions are necessary to become a PU. 


\subsection{Formation and Processes}

Table 1 illustrates the word-formation rules (4) that apply to the PUs in (1) based on the syntactic and semantic features. However, PUs such as how come ...?/why ...?, shoulds or oughts working as nouns, and those that implying people are excluded because they do not syntactically change at all.

Table 1. How PUs are formed

\begin{tabular}{|c|c|c|c|}
\hline PUs & formation rule & reason & $\begin{array}{l}\text { continuous/ } \\
\text { discontinuous }\end{array}$ \\
\hline you know what & shortening & $\begin{array}{l}\text { a proposition like actually happened of you } \\
\text { know what actually happened etc. is cut } \\
\text { down }\end{array}$ & continuous \\
\hline $\begin{array}{l}\text { here we go/ } \\
\text { here we go again }\end{array}$ & inversion & $\begin{array}{l}\text { here is put at the beginning of a sentence to } \\
\text { call for attention }\end{array}$ & continuous \\
\hline let's say & contraction & let us say & continuous \\
\hline go do & shortening & to of go to do drops & continuous \\
\hline and yet/ but yet & compounding & [and/ but $]+[$ yet, still, then, etc. $]$ & continuous \\
\hline until to/ up until to & blending & until, to, up & continuous \\
\hline it looks that-clause & analogy & it seems that-clause & continuous \\
\hline from -ed form to $\varphi$ form & shortening & $\mathrm{n} / \mathrm{a}$ & continuous \\
\hline in and of itself & blending & in itself, of itself & continuous \\
\hline in and of & backformation & in and of itself & continuous \\
\hline be on against & metaanalysis & [be on][against] & continuous \\
\hline be in and out & shortening & Of of be in and out of drops & continuous \\
\hline be in to & metaanalysis & [be in] [to] & continuous \\
\hline as it was & merging & subjunctive were & continuous \\
\hline though A but B & compounding & [though] ... [but] & discontinuous \\
\hline not A though A' but B & compounding & not A but B, though A but B & discontinuous \\
\hline not only A though A' but B & compounding & not only $\mathrm{A}$ but $\mathrm{B}$, though $\mathrm{A}$ but $\mathrm{B}$ & discontinuous \\
\hline from A until to B & compounding & from $\mathrm{A}$ to $\mathrm{B}$, until to & discontinuous \\
\hline
\end{tabular}

From Table 1 we can see that PU formations can be classified into three types, as shown in (13).

(13) a. an approach that applies word-formation rules: compounding (5), shortening (4), blending (2), metaanalysis (2), backformation (2)

b. a semantic and morphological approach adopting general linguistic rules: conversion (1), contraction (1)

c. a sheer semantic approach: analogy (1), merging (1)

The numbers in the round brackets in (13) show the number of times each rule or method was used in Table 1. In (13a), it is clear that highly productive general word-formation rules such as compounding, derivation, acronym, and backformation are not always observed in the formation of PUs. The rules applied in (13b) are general linguistic rules with a high regard for semantics as they do not cause semantic misinterpretation. The methods used in (13c) show the PUs genuinely formed from a semantic perspective. The methods in (13b, c) are not frequently employed compared with (13a), but prove that PUs are formed with a focus on semantics beyond the scope of grammatical rules. It can be assumed that word-formation rules are mainly adopted in the formation of PUs, but PUs can also be formed using unique methods such as a combination of morphology and semantics or using a semantic method. Also, PUs can be formed by applying a rule or method irrespective of whether it is a continuous or discontinuous PU.

The methods as to how PUs are formed are shown in (14).

(14) PUs

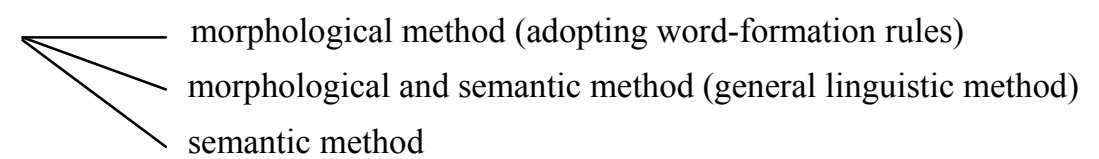

type A

type B

type C

At this point, care must be taken that type B is an intermediary for type A and type C. From this discussion including (14), it can be observed that PUs are formed not as linear constructions but as steric constructions.

From the outcomes shown in (13) and (14), (15) summarizes the process as to how a word combination becomes a PU. 
(15) (i) two existing words are put together by adopting either (i) a morphological method, (ii) a morphological and semantic method, or (iii) a semantic method, which then become a repeatedly used unit

\section{$\downarrow$}

(ii) a PU has its own meaning and function through repeated use

$\downarrow \leftarrow$ with the assistance of the lexicalization of phrases

(iii) the PU is established as an independent lexical item

As (15) describes, first the PUs are formed through the combination of two existing words, as in the Kenning used in OE, and shaped using a specific method. Second, the PUs develop individual features through frequent use. With the assistance of phrasal lexicalization, one of the word-formation rules, a PU becomes an independent unit. These processes hold true for all PUs regardless of whether they are continuous or discontinuous.

\subsection{Conditions}

Criteria for determining whether a word-combination is a PU or not are defined in (16).

(16) a. frequency

b. dispersion

c. fixedness (i.e., no variables)

d. consistency of existing words (e.g., Kenning in Old English)

Frequency and dispersion $(16 \mathrm{a}, \mathrm{b})$ are the norms indicating that PUs do not arise by accident. Fixedness (16c) is the necessary condition that indicates that the fixed form of the PU has widespread use in any context or situation, meaning that PUs are polysemic and multifunctional. In (16d), newly observed PUs are formed through a combination of existing words. If such combinations are not frequently and widely used, they are not PUs.

Why do PUs consist of existing words, and especially of function words? As culture develops due to technological improvements, new concepts are developed. Because it is time consuming to develop new words or expressions, there is a tendency to use existing words. However, even when new expressions are generated, it takes time for them to become widely used because of misunderstandings regarding the meaning and function. For example, when the Christian mission started in 597, it was difficult to express the new Christian concepts using existing words, so people at that time borrowed words or combined existing words to explain the new concepts. This same process occurs in contemporary English; the principle of linguistic economy (Note 10) is used in the formation of PUs, as Makkai (1975) comments in (17).

(17) the most probable reason is that as we develop new concepts, we need new expressions for them, but instead of creating a brand new word from the sounds of language, we use some already existent words and put them together in a new sense. This, however, appears to be true of all known language. (Makkai, 1975, p. vi)

Next, why are function words put together? If a PU consists of content words, it would a take long time for the lexical meanings inherent in each content word to become weak enough for the PU to develop its own unique meaning; that is, content words are not semantically transparent. On the other hand, function words are semantically unmarked, so it is easier for the unique PU meanings to develop. As with Kenning, PUs can be formed by adopting one of the methods in (14), undergoing the processes in (15), and fulfilling the conditions in (16). Some PUs behave as content words, which is discussed in the next section.

\section{Degrammaticalization of PUs}

In this section I examine whether the PUs consisting of function words as shown in (3b) cause degrammaticalization, and if so, how this degrammaticalization occurs.

\subsection{From a Functional Perspective}

Table 2 summarizes the PUs shown in (3b) that cause degrammaticalization from a functional perspective. 
Table 2. Degrammaticalizationof PUs formed from function words

\begin{tabular}{llll}
\hline PUs & original function & a function in a context & $\begin{array}{l}\text { continuous/ } \\
\text { discontinuous }\end{array}$ \\
\hline until to/ up until to & complex preposition & preposition & continuous \\
in and of & prepositional phrase & preposition & continuous \\
be on against & prepositional phrase & verb & continuous \\
be in and out & prepositional phrase & verb & continuous \\
be in to & prepositional phrase & noun & continuous \\
nouns of auxiliary verbs & auxiliary verb & conjunction & discontinuous \\
though A but B & correlative conjunction & conjunction & discontinuous \\
not A though A' but B & correlative conjunction & conjunction & discontinuous \\
not only A though A' but B & correlative conjunction & preposition & discontinuous \\
from A until to B & complex preposition & &
\end{tabular}

From Table 2, it is apparent that the PUs, be on against, be in and out, be in to, and auxiliary verbs working as nouns clause degrammaticalization. The other PUs (until to/up until to, in and of, though $\mathrm{A}$ but $\mathrm{B}$, not $\mathrm{A}$ though $\mathrm{A}^{\prime}$ but $\mathrm{B}$, not only $\mathrm{A}$ though $\mathrm{A}^{\prime}$ but $\mathrm{B}$, from $\mathrm{A}$ until to $\mathrm{B}$ ) are discussed later.

The PUs, be on against, be in and out, be in to, and auxiliary verbs working as nouns fulfill the definition of degrammaticalization shown in (12a). They also undergo a single process from grammatical word -> content word, as in (12b). This process is equivalent to the degrammation shown in (12c). Unlike degrammaticalization, which has been studied so far, the least phenomenon is observed in the case of degrammaticalization of PUs. The PUs, be on against, be in and out, be in to, and auxiliary verbs behaving as nouns meet the judgement criteria in (12d), meaning that some PUs consisting of function words can cause degrammaticalization. However, from a syntactic standpoint, care must be taken as it is rare for PUs comprised of function words to reach degrammaticalization.

\subsection{From a Semantic Perspective}

The PUs (until to/up until to, in and of, though A but $\mathrm{B}$, not A though A' but $\mathrm{B}$, not only $\mathrm{A}$ though A' but $\mathrm{B}$, from A until to $\mathrm{B}$ ) that do not reach degrammaticalization indicate a new semantic degrammaticalization. Examples of each of the PUs shown in Table 2 are shown below from (18) to (29) (italicized by the author). Please note that the examples below include PUs that are the result of degrammaticalization.

(18) This means that average household size in Great Britain fell from about 3.21 to about 2.56 persons over this period and this decline is expected to continue at least until to the end of the century.

(Inoue, 2011, p. 160; BNC)

(19) For the past five years and up until to last May, very few people took part in.... (Inoue, 2011, p. 163; OEC)

(20) The static, insular view ascribed to cognitive semantics is deemed incapable of handling the dynamic, intersubjective, context dependent nature of meaning construction in actual discourse. In and of itself, the interactive alternative is certainly correct. It is not however an alternative-its essential ideas are in fact accepted as basic tenets of cognitive semantics.

(Inoue, 2013b, p. 1; Langacker, 2008, p. 28)

(21) We should listen to people's stories and help them see the value in and of their life experiences.... (Inoue, 2013b, p. 12; COCA, 2006, written)

(22) KING: One hour?

MCGRAW: It's going to be an hour.

KING: You said 3:00, 4:00 in the afternoon. Are you going to be on against Oprah?

MCGRAW: Oh, absolutely not. My mama didn't raise a fool.

KING: Is that part of the rule, you can't be placed on a station...

MCGRAW: When we decided to do this, Oprah has created the show, of course. So there's no sense in us working at cross purposes. So if she's on at 4:00 in the afternoon, I'm generally on at 3:00. If she's on at 3:00, I'm on at 4:00. (Inoue, 2014, p. 78; Larry King Live, Feb., 2002)

(23) When he gets a text message from his son that reads I love you, Dad, he's alarmed. He calls the son in 
California. "Hey, Tom. I just got your note. I'm here at the office, well, I'm in and out all day. Okay. I'll talk to you soon. I hope you're well." But the son doesn't call back....

(Inoue, 2013a, p. 148f.; COCA, written, 2010)

(24) WHITFIELD So, is it feasible, in your opinion, to think that a shuttle could be launched by this fall?

CABBAGE: I think it's feasible. But I think it may be in to 2005 before the shuttle actually does fly. There are a lot of people within NASA who think that it's going to take that long, not only to make the organizational changes, get them underway, but also hardware changes they'll have to make as well. (Inoue, 2014, p. 80; COCA, spoken, 2004)

(25) BOAZ: It might very well. (sic. It might be very well.) You know, they start out saying, it's just $a$ should, and then they say, OK, it's a must. (CROSSTALK) (Inoue, 2015, p. 148; COCA, spoken, 2002)

(26) An incredible 83 per cent of voters quizzed in the Republic said they would say Yes to the deal. And, of the rest, three in four had not made up their minds on which way to cast their vote. There is some opposition to the deal though — but it is tiny. Just over three per cent of people said they would definitely say No. (Inoue, 2013c:86; WB)

(27) Her eyes were drawn back to the set, where Dane was still holding court. Somehow he was able to dwarf everyone else around him, not just by his size, though that was considerable, but by sheer presence, so that, even though he was surrounded by half a dozen or more people, the casual onlooker would be aware only of him. (Inoue, 2013c, p. 86; BNC)

(28) But in the 1950s, with the first wave of postwar affluence, young people in transition began to have money and the adman found them a place in the consumer society. This was the period which saw a revolution in popular music and the beginning of rock'n'roll. With it came not only new though ephemeral music, but new clothes, magazines, books and films. (Inoue, 2013c, p. 86; BNC)

(29) chartered flights are being offered from Dec. 27 until to Feb. 28 for the convenience of passengers....

Reviewing the semantics in the above examples, it can be seen that all PUs cause degrammaticalization, as contexts without the PUs do not make sense. To put it another way, PUs formed from function words that behave as content words are semantically essential to the sentences. This is also clear by the informants' elicitations (Note 11). The PUs, therefore, semantically cause degrammaticalization as the PUs carry the meanings. The results obtained from this research reveal that PU semantic degrammaticalization is common, but PU syntactic degrammaticalization is less common.

\section{Conclusion}

The points to be made from this study are shown in (30).

(30) a. the methods as to how word-combinations become PUs $->$ refer to Table 1 and (14)

b. the process the word-combinations undergo to become PUs $->$ refer to (15)

c. the conditions needed to become PUs -> refer to (16)

d. the reason why newly observed PUs tend to consist of function words -> the principle of least effort

e. Do PUs formed from function words cause degrammaticalization? -> Yes, they do, but they mainly cause semantic degrammaticalization.

f. the process as to how PUs cause degrammaticalization -> grammatical words -> content words

The results in (30) indicate that this study is significant for two reasons: (i) a theoretical aspect (i.e., degrammaticalization) is added to the phraseology, which was examined using a bottom-up approach, and (ii) degrammaticalization is applicable not only to words but also to PUs.

\section{Acknowledgment}

This research was made possible by the Grant-in-Aid for Young Scientists (B) (Grant number 15K16779). I would like to thank the Japan Society for the Promotion of Science.

\section{References}

Allen, M. (1978). Morphological investigation. Ph.D. Dissertation, University of Connecticut.

Bauer, L. (1983). English Word Formation. Cambridge: Cambridge University Press. http://dx.doi.org/10.1017/CBO9781139165846 
Bybee, J. L. (1985). Morphology. Amsterdam: John Benjamins. http://dx.doi.org/10.1075/tsl.9

Givón, T. (1975). Serial verbs and syntactic change: Niger-Congo. In C. Li (Ed.), Word Order and Word Order Change (pp. 47-112). Austin: University of Texas Press.

Gray, B., \& Biber, D. (2015). Phraseology. In D. Biber \& R. Reppen (Eds.), The Cambridge Handbook of English Corpus Linguistics (pp. 125-145). http://dx.doi.org/10.1017/CBO9781139764377.008

Greenberg, J. (1991). The last stages of grammatical elements: Contractive and expansive desemanticization. In C. E. Traugott \& B. Heine (Eds.), Approaches to Grammaticalization I (pp. 301-314). Amsterdam: John Benjamins. http://dx.doi.org/10.1075/tsl.19.1.14gre

Haspelmath, M. (2004). On directionality in language change with particular reference to grammaticalization. In O. Fischer, M, Norde, \& H. Perridon (Eds.), Up and Down the Cline: The Nature of Grammaticalization (pp. 17-44). Amsterdam: John Benjamins. http://dx.doi.org/10.1075/tsl.59.03has

Hopper, P. J., \& Traugott, E. C. (2003). Grammaticalization (2nd ed.). Cambridge: Cambridge University Press. http://dx.doi.org/10.1017/CBO9781139165525

Inoue, A. (2009). A problem of phonetic notation-stress patterns of set phrases including "day" in dictionaries. English Phonetics, 13, 125-134.

Inoue, A. (2011a). The principle of least effort in present-day English: from "pirated version" to "pirate version," and related phenomena. In K. Yagi, T. Kanzaki, \& A. Inoue (Eds.), Phraseology, Corpus Linguistics and Lexicography (Papers from Phraseology 2009 in Japan, pp. 151-165). Nishinomiya: KwanseiGakuin University Press.

Inoue, A. (2011b). A phraseological approach to finding the functions of newly observed compound prepositional phrases until to and up until to in contemporary English. Lexicography: Theoretical and Practical Perspective (pp. 160-169). (ASIALEX (Asian Association for Lexicography) '11 Proceedings).

Inoue, A. (2013a). Newly observed phraseological units in present-day English: the example of be in and out. Lexicography and Dictionaries in the Information Age (pp. 145-150). Selected papers from the 8th ASIALEX International Conference.

Inoue, A. (2013b). Gendaieigonikansatsusarerushinkasuruatarashiiteikeihyougen to sonjittai-yuugoukei in and of itself to haseikei in and of wo reitoshite (Evolutionary phraseological units in contemporary English-in and of itself as a merged form and in and of as a directive form). The JASEC Bulletin, 22(1), 1-15.

Inoue, A. (2013c). A phraseological approach to understanding the function of a new correlative conjunction observed in contemporary English-though A but B. Research on Phraseology Across Continents (Intercontinental Dialogue on Phraseology), 2, 79-96. Bialystok: University of Bialystok Publishing House.

Inoue, A. (2014). Actual behaviors of newly observed phraseological units comprising two prepositions. International Journal of English Linguistics, 14(4), 74-87. http://dx.doi.org/10.5539/ijel.v4n4p74

Inoue, A. (2015). Newly observed phraseological units with noun forms of modal verbs. Lexicography: Journal of ASIALEX, 1(2), 37-57.

Ito, T., \& Sugioka, Y. (2003). Go no Shikumi to Gokeisei (Word's Mechanisms and Word-Formation Rules). Tokyo: Kenkyuusha.

Johansson, S. (1985). Grammatical tagging and total accountability. In S. Bäckman \& G. Kjellmer (Eds.), Papers on Language and Literature Presented AlvarEllegård Erik Fryman. (Gothenburg Studies in English 60) (pp. 208-219). Göteborg: ActaUniversitatisGothoburgensis.

Langacker, R. W. (1977). Syntactic reanalysis. In N. C. Li (Ed.), Mechanisms of Syntactic Change (pp. 57-139). Austin: University of Texas Press.

Langacker, R. W. (2008). Cognitive Grammar: A Basic Introduction. Oxford: Oxford University Press. http://dx.doi.org/10.1093/acprof:oso/9780195331967.001.0001

Leech, G. (1992). Corpora and theories of linguistic performance. In J. Svartvik (Ed.), Directions in Corpus Linguistics: Proceedings of Nobel Symposium (pp. 4-8, 105-122). http://dx.doi.org/10.1515/9783110867275.105

Lehmann, C. (1982). Thoughts on Grammaticalization. München: Lincom Europe.

Lieber, R. (1983). Argument Linking and Compounds in English. Linguistic Inquiry, 251-286. 
Makkai, A. (1975). A Dictionary of American English Idioms. New York: Barron's.

Nishikawa, M. (2013). EigoSetsuji no Miryoku-GoiryokuwoTakameru Tango no Mechanism (Fascinating English Affix - The Mechanisms of Words to Build a Strong Vocabulary). Tokyo: Kaitakusha.

Norde, M. (2009). Degrammaticalization. Oxford: Oxford University Press. http://dx.doi.org/10.1093/acprof:oso/9780199207923.001.0001

Norde, M. (2010). Degrammaticalization: three common controversies. In K. Ekkehard, E. Gehweiler, \& K. Stathi (Eds.), What's New in Grammaticalization? (pp. 123-150). Amsterdam: John Benjamins. http://dx.doi.org/10.1075/slcs.119.08nor

Pinker, S. (1994). The Language Instinct: How the Mind Creates Language. New York: William Morrow. http://dx.doi.org/10.1037/e412952005-009

Plag, I. (2003). Word-Formation in English. Cambridge: Cambridge University Press.

Ramat, P. (1992). Thoughts on grammaticalization. Linguistics, 30, 549-560. http://dx.doi.org/10.1515/ling.1992.30.3.549

Siegel, D. (1974). Topics in English Morphology. New York: Garland.

Vincent, N. (1980). Iconic and symbolic aspects of syntax: Prospects for reconstruction. In P. Ramat (Ed.), Linguistic Reconstruction and Indo-European Syntax (pp. 49-68). Amsterdam: John Benjamins. http://dx.doi.org/10.1075/cilt.19.06vin

Yagi, K., \& Inoue, A. (2013). EigoTeikeihyougenKenkyu—Rekishi, Houhou, Jissen (English Phraseology—Its History, Method, and Practice). Tokyo: Kaitakusha.

Yamauchi, N., \& Kitabayashi, T. (2014). GendaiEigogaku no Approach (Approach to Contemporary English Linguistics). Tokyo: Eihousha.

\section{Notes}

Note 1. The PUs under study are those in (1) and: dart in and out, make out like a bandit, the ball is in your court., I wasn't born yesterday, contract in/out, quite the contrary, carry the day, day after day, day by day, day in, day out, from day one, from day to day, from one day to the next, make sb's day, don't have all day, in this day and age, the soup of the day, one of the these days, one of those days, some day, one day, that'll be the day, these days, those were the days, to the day, and to this day.

Note 2. Content words include nouns, verbs, adjectives, (conjunctive) adverbs, demonstrative pronouns, reflexive pronouns, numerals, and interrogatives.

Note 3. Function words include prepositions, conjunctions, articles, relatives, be-verbs, auxiliary verbs, and pronouns.

Note 4. Words such as compounds or derivatives are trimmed down based on an error analysis, and then new words are coined (e.g., beggar $->$ beg)

Note 5. Frequently-used proverbs become a phrase using hyphenation such as catch-me-if-you-can and passer(s)-by.

Note 6. According to Norde (2009, p. 107f.), Greenberg (1991) first introduced the term for a shift in the function of heavily grammaticalized grams (i.e., grammatical morpheme). Although regrammaticalization changes are sometimes cited as potential counterexamples to grammaticalization, they differ from degrammaticalization in that the grams do not become 'less grammatical.' Rather, they substitute one grammatical function for another, and for this reason they are more appropriately regarded as instances of lateral shift.

Note 7. Norde (2009, p. 108) noted that antigrammaticalization was proposed by Haspelmath (2004) to replace the term grammaticalization. Antigrammaticalization covers "any type of change that goes against the general direction of grammaticalization (i.e., discourse $>$ syntax $>$ morphology)" (Norde, 2009, p. 108; Haspelmath, 2004, p. 28). This term was coined to separate true exceptions to unidirectionality from other changes that had been labeled degrammaticalization. Anti-grammaticalization corresponds with the "debonding" and "deinflectionalization" used in the study.

Note 8. Ramat (1992)'s term. The definition is as follows: "encompassing most changes that result in new lexemes, with the exception of regular word formation" (Norde, 2009, p. 112). 
Note 9. A gram is the abbreviation of grammatical morphemes.

Note 10. Linguistic economy has two principles: the principle of least effort and the principle of redundancy. The essential role of a language is to maintain effective communication. The two principles are thought to be responsible for changes in languages without giving a false impression of the essential role. For example, we tend to choose and use an easier and simpler way of saying things such as "pirate version" because of the underlying principle of least effort. In contrast, we can find examples such as "until to Friday," which are somewhat excessive. It is quite safe to assume that the speaker must have thought that "until Friday" might give a false impression to the hearer, so he/she added "to," which functions similarly as "until." To put it another way, wordy expressions, such as "until to Friday," appear as a consequence of the underlying principle of economy. (Inoue, 2011a, p. 160).

Note 11. I asked native speakers of English (American, Britons, Canadian, and Australians). All responded that the sentences without the PUs made no sense. The detailed results are shown in Inoue (2011b, 2013a, 2013b, 2013c, 2014, 2015).

\section{Corpora}

BNC: British National Corpus

WB: Word Banks Online

OEC: Oxford English Corpus

LKL: Larry King Live Corpus

COCA: The Corpus of Contemporary American English

\section{Copyrights}

Copyright for this article is retained by the author(s), with first publication rights granted to the journal.

This is an open-access article distributed under the terms and conditions of the Creative Commons Attribution license (http://creativecommons.org/licenses/by/3.0/). 